ORIGINAL ARTICLE

\title{
Assessment of Self-Medication and Their Associated Risks in Medical and Non-Medical People of Sialkot: Cross-Sectional Study
}

\author{
HADAYAT $^{5}$, TALHA LAIQUE ${ }^{6 *}$ \\ ${ }^{1}$ Department of Community Medicine, Islam Medical College, Sialkot-Pakistan \\ ${ }^{2}$ Department of Community Medicine, Karachi Institute of Medical Sciences, Karachi-Pakistan \\ ${ }^{3}$ Department of Pharmacology, Islam Medical College, Sialkot-Pakistan \\ ${ }^{4}$ Department of Medicine, Fauji Foundation Medical College, Rawalpindi-Pakistan \\ ${ }^{5}$ Department of Orthopedic-Surgery, Islam Medical College, Sialkot-Pakistan \\ ${ }^{6}$ Department of Pharmacology, Allama labal Medical College, Lahore-Pakistan \\ ${ }^{*}$ Correspondence to: Dr. Talha Laique, Email: talhalaique51@gmail.com, Tel:+92-331-0346682
}

YASIR SADIQ ${ }^{1}$, KANWAL KHALID², AMTUL HAFEEZ ${ }^{3}$, MIRZA MUHAMMAD ABDULLAH ${ }^{1}$, MUDASSAR NAZAR $^{4}$, AISHA

\begin{abstract}
Self-medication is an important health issues among patients' behavior in reaction to their ailment.

Objectives: To assess self-medication practices and their associated risks in medical \& non-medical people of

Sialkot, Pakistan.

Study Design: Cross sectional study.

Methodology: Present study enrolled 250 subjects from Sialkot between October-November 2020 through selfadministered web-based questionnaire. It assessed demographic details, prevalence and practice of selfmedication along-with the attitude of respondents towards self-medication and associated side effects.

Statistical analysis: Data was analyzed by SPSS, v-24.

Results: Among enrolled subjects, mean age was $21 \pm 1.8$ years. Female: Male percentages were $(59.4 \%$ : $40.2 \%)$. Self-medication was common among $85 \%$ subjects. The most common reason for self-medication in medical people was to need a quick relief $(42.9 \%)$ and in non-medical people were previous experience with symptoms $(35.2 \%)$

Conclusion: We concluded that habit of self-medication is a common practice among educated generation knowing the fact that it harms their lives. Hence, need of hour is to educate them in-order to ensure safe practices.
\end{abstract}

Key Words: Self Medication, Prevalence and Risk Factors.

\section{INTRODUCTION}

Self-medication is an important health issues among patients' behavior in reaction to their ailment. ${ }^{1}$ It's a common practice adopted by most individuals who never seek a doctor for minor ailments. WHO considers selfmedication as part of the self-care that helps efficient use of the burdened health care system with guidelines for the regulatory assessment of medicinal products for use in selfmedication. ${ }^{2,3}$ According to literature review self-medication needs certain level of knowledge about drug before administration.

Factors like age, sex, income, self-care orientation and medical knowledge influence its administration as revealed by previous works. ${ }^{4}$ Among healthcare workers, this is a more common practice in developed countries because they have better knowledge than general population but it is mostly same in medical as well as nonmedical people in developing countries. ${ }^{5}$

Today, the term 'responsible' self-medication is commonly employed than, over the counter (OTC) drugs as it is limited only to the situations for which they are necessary as shown by previous researches. ${ }^{6}$ Irrational use of drugs is now becoming a concern among people. The Prevalence rates of self medication are on the rise globally as estimated $68 \%$ in European countries whereas much higher prevalence $(92 \%)$ in the developing countries like Kuwait, Pakistan, India and Nepal. ${ }^{7-9}$ However, this is an alarming situation in terms of its prevalence rates despite all efforts.
Although it's a fact that it treats minor ailments, saves time and hence reduces burden of patients in tertiary care hospitals particularly in developing countries with limited health care resources. One major concern is the availability complex drugs like antibiotics without prescriptions as revealed by previous studies ${ }^{10}$. Although, this practice gives birth to problems like multi-drug resistance, dependence and addiction thus leading to misdiagnosis, drug interactions causing different side effects among sufferers. ${ }^{11-13}$

In our clinical setups and society, self-medication is easy, where drug resistance is emerging due to its dispense by inexpert persons. Hence, in the light of above description present study was planned as it will provide useful insight on the reasons for which patient resort to this practice.

Objectives: To assess self-medication practices and their associated risks in medical \& non-medical people of Sialkot, Pakistan.

Methodology: Present study enrolled 250 subjects from Sialkot between October-November 2020 through selfadministered web-based questionnaire. It assessed demographic details, prevalence and practice of selfmedication along-with the attitude of respondents towards self-medication and associated side effects. The questionnaire included primarily close ended question. Some of the questions may tolerate more than one answer (example: reasons for self-medication). Informed written consent was taken and all information was kept 
confidential. The main outcome measures were used to compare healthcare and non-healthcare people.

Statistical Analysis: Statistical analysis was performed for each question by (SPSS) Statistical procedure for social sciences version 24.0. Descriptive analysis was done. Inferential analysis was done using the frequency tables. With the help of descriptive statistic, we checked the normality of data and remove all the out layers then run the descriptive analysis and generate the results.

\section{RESULTS}

Parameters like gender, age of respondents, field of education, adverse effects of drugs were presented as frequency and percentage among 251 enrolled subjects as shown in table-1.

\begin{tabular}{|l|l|l|l|}
\hline Table-1: General Features Of Enrolled subjects $(\mathrm{n}=251)$ & \multicolumn{2}{l|}{} \\
\hline Variables & Categories & Frequency & Percentage $(\%)$ \\
\hline \multirow{3}{*}{ Gender } & Female & 149 & 59.4 \\
\cline { 2 - 4 } & Male & 101 & 40.2 \\
\cline { 2 - 4 } Age (years) & Other & 1 & .4 \\
& Below 18 & 14.7 \\
\cline { 2 - 4 } & $18-30$ & 37 & 75.7 \\
\cline { 2 - 4 } & Above 30 & 190 & 9.6 \\
\hline Respondent's Field of Study & Medical & 24 & 50.2 \\
\cline { 2 - 4 } & Non-Medical & 126 & 49.8 \\
\hline Adverse effect of Medication in Medical Group & Yes & 125 & 28.8 \\
\cline { 2 - 4 } & No & 37 & 71.2 \\
\hline Adverse effect of Medication in Non-Medical Group & Yes & 89 & 23.8 \\
\cline { 2 - 4 } & No & 30 & 76.2 \\
\hline
\end{tabular}

The most common factor that led to self-medication in Medical people was found to "Need a quick relief" $(42.9 \% \mathrm{n}=54)$ and self-perception of "Trivial nature of the problem" $(25.4 \% \mathrm{n}=32)$ and in Non-medical people it was "Similarity of symptoms with past illness" $(35.2 \% \mathrm{n}=44)$ as shown in table-2.

\begin{tabular}{|l|l|l|l|}
\hline Table-2: Reasons For Self-Medications Among Enrolled Subjects ( $\mathrm{n}=251)$ & Frequency & Percentages (\%) \\
\hline Variables & Categories & 54 & 42.9 \\
\hline Reasons for Self-Medication in Medical Group & Quick relieve & 32 & 25.4 \\
\cline { 2 - 4 } & Perceive illness as mild & 18 & 14.3 \\
\cline { 2 - 4 } & Similarity of symptoms with past illness & 13 & 10.3 \\
\cline { 2 - 4 } & Dissatisfaction from health care system & 09 & 7.1 \\
\cline { 2 - 4 } & Others & 33 & 26.4 \\
\hline \multirow{4}{*}{ Reasons for Self-Medication in Non-Medical Group } & 31 & 24.8 \\
\cline { 2 - 4 } & Quick relieve & 44 & 35.2 \\
\cline { 2 - 4 } & Perceive illness as mild & 14 & 11.2 \\
\cline { 2 - 4 } & Similarity of symptoms with past illness & 3 & 2.4 \\
\cline { 2 - 4 } & Dissatisfaction from health care system & Others & 3 \\
\cline { 2 - 4 }
\end{tabular}

Reason for self-medication included headache (19.8\%), flu (16.7\%) and fever (16.7\%) in Medical people and pain $(26.4 \%)$, headache $(23.2 \%)$ like symptoms are common in Non-medical people as shown in table-3.

\begin{tabular}{|c|c|c|c|}
\hline Variables & Categories & Frequency & Percentages (\%) \\
\hline \multirow{8}{*}{ Reasons for Self-Medication in Medical Group } & Headache & 25 & 19.8 \\
\hline & Acne / skin diseases & 6 & 4.8 \\
\hline & Cold/ flu & 21 & 16.7 \\
\hline & Cough & 14 & 11.1 \\
\hline & Fever & 21 & 16.7 \\
\hline & Stomachache/ Heart Burn & 7 & 5.6 \\
\hline & Allergy & 10 & 7.9 \\
\hline & Pain & 22 & 17.5 \\
\hline \multirow{8}{*}{ Reasons for Self-Medication in Non-Medical Group } & Headache & 29 & 23.2 \\
\hline & Acne / skin diseases & 9 & 7.2 \\
\hline & Cold/ flu & 12 & 9.6 \\
\hline & Cough & 7 & 5.6 \\
\hline & Fever & 12 & 9.6 \\
\hline & Stomachache/ Heart Burn & 5 & 4.0 \\
\hline & Allergy & 4 & 3.2 \\
\hline & Pain & 47 & 37.6 \\
\hline
\end{tabular}

The most commonly used drugs for self-medication were presented as percentage in table-4. Approximately, $85 \%$ of the respondents admitted to self-medication practice. 


\begin{tabular}{l|l|l|}
\hline Table-4: Commonest Drugs Used To Self-Medicate & Percentages \\
\hline Variables & Categories & $(88.3 \%)$ \\
\hline \multirow{5}{*}{ Reasons for Self-Medication in Medical Group } & Pain killers & $(65.1 \%)$ \\
\cline { 2 - 3 } & Fever relieving meds & $(44.1 \%)$ \\
\cline { 2 - 3 } & Anti-allergy & $(44.1 \%)$ \\
\cline { 2 - 3 } & Vitamins & $(35.2 \%)$ \\
\cline { 2 - 3 } & Antibiotics & $(18.6 \%)$ \\
\cline { 2 - 3 } & Pills for indigestion & $(10.1 \%)$ \\
\cline { 2 - 3 } & Sleeping pills & $(7.4 \%)$ \\
\cline { 2 - 3 } & Herbal/Homeopathic & \\
\end{tabular}

Attitude towards self medication among people was presented as frequency and percentage as shown in table-5. Table-5: Attitude Towards Self Medications Among Subjects ( $\mathrm{N}=251)$

\begin{tabular}{|l|l|l|l|}
\hline Variables & Categories & Frequency & Percentages (\%) \\
\hline \multirow{2}{*}{ Practicing Self-Medication in Medical Group } & Acceptable Practice & 79 & 59.5 \\
\cline { 2 - 4 } & Somewhat Acceptable & 36 & 28.6 \\
\cline { 2 - 4 } & Not Acceptable & 15 & 11.9 \\
Practicing Self-Medication in Non-Medical Group & Acceptable Practice & 64 & 51.2 \\
\cline { 2 - 4 } & Somewhat Acceptable & 29 & 23.2 \\
\cline { 2 - 4 } & Not Acceptable & 32 & 25.6 \\
\hline
\end{tabular}

\section{DISCUSSION}

The objective of this research is to assess self-medication practices and their associated risks in medical \& nonmedical people of Sialkot, Pakistan. When the prescribed drug is unaffected, health workers reported that $(43.3 \%)$ of them altered the drug dosage themselves according to the course of the symptoms. However, $(61.9 \%)$ of general population reported that they intentionally stopped medication on the ablation of symptoms. Ironically, majority of people $(87.4 \%)$ were aware of harmful effects by selfmedication. However, around (28.8\%) medical related people perceive side effects of self-medication and $(23.8 \%)$ of non-medical people. Our findings were in line with many previous studies that showed less side effects and high awareness levels. ${ }^{14-16}$

Attitudes towards this practice was alarming even among educated youth thus depicting catastrophic situation. Despite the fact shown by results that self-medication is harmful, this is a well accepted practice among population thus indicating their lack of complete knowledge about drugs adverse events. A study held in Turkey showed similar results that $89 \%$ of their subjects were aware of the fact that use of drugs without prescription was wrong yet $45 \%$ subjects were indulged in self-medication according to survey. ${ }^{17}$ In our study people also reported the common side effects related to this practice in which drowsiness, nausea, constipation is common in both groups.

No such study was done previously locally at Sialkot although on national level many studies were done that showed its high prevalence. Our results also showed high prevalence similarly that requires serious attention. Noteworthy point is its high prevalence among educated population thus depicting worse scenes among un educated pupils. Our results were in line with many previous studies that showed similar high self medication prevalence. ${ }^{18,19}$

Unfortunately, there was insignificant difference in its prevalence rates amongst medical and non-medical students. One reason may be that health workers especially medical students have more knowledge about medicines that may drift them towards this practice. Various previous studies showed similar trends among medical students and health workers. Hence our results were similar to many documented studies. ${ }^{20,21}$ On the other hand, even depleted knowledge of drugs among nonmedical persons failed to stop them from self-medication depicting lack of knowledge about its drastic adverse effects on health. However, it is certainly an interesting prospect for future research to find reasons for lack of awareness among pupils.

It is disastrous to let pharmacies and medical stores continue as the way they do in Pakistan because easy pharmacy access with drug stocks being kept at homes. Recent studies showed that acquaintance and easy access to drugs are major determinants for this practice. ${ }^{22,23}$ According to previous studies, advertising adverse effects of drugs have directly affected youth's decision to self-medicate. ${ }^{24,25}$ Thus, strict rules and monitoring are required to stop this ill-activity. Limitations: Our study had limitations like financial constraints, lack of resources, small sample size, and questionnaire was a self-reported.

\section{CONCLUSION}

We concluded that habit of self-medication is a common practice among educated generation knowing the fact that it harms their lives. Hence, need of hour is to educate them in-order to ensure safe practices. Strict policies need to be implemented on the advertising and selling of medications to prevent this problem from escalating.

Acknowledgments: All Authors are thankful to Allah who made it possible.

Authors' Contribution:

YS \& KK: Conception and design of work

$\mathrm{AH}$ \& MMA: Collecting and analyzing the data

$\mathrm{MN}, \mathrm{AH}$ \& TL: Drafting and revising the manuscript for intellectual content.

Conflict of Interest: None to declare

Financial Disclosure: None

\section{REFERENCES}

1. Montastruc JL, Bagheri H, Geraud T, Lapeyre-Mestre M. [Pharmacovigilance of self-medication]. Therapie 1997; 52: 105-10. 
2. Filho L, Antonio I, Lima-Costa MF, Uchoa E. Bambui Project: a qualitative approach to self-medication. Cad Saude Publica 2004; 20: 1661-9.

3. Bretagne JF, Richard Molyoivd B, Honnorat C, Caekaert A, Barthelemy P.[Gastroesophageal reflux in the French general population: national survey of Its]. Presse Med 2006; 35: 23-31.

4. Shankar PR, Partha P, Shenoy N. Self-medication and nondoctor prescription practices in Pokhara valley, Western Nepal: a questionnaire-based study. BMC Fam Pract 2002; 3: 17.

5. Abahussain E, Matowe LK, Nicholls PJ. Self-reported medication use among adolescents in Kuwait. Med Princ Pract 2005; 14: 161-4.

6. Deshpande SG, Tiwari R. Self medication--a growing concern. Indian J Med Sci 1997; 51: 93-6.

7. Haider $\mathrm{S}$, Thaver $\mathrm{IH}$, Self medication or self care: implication for primary health care strategies. J Pak Med Assoc 1995; 45: 297-8.

8. Hsiao FY, Alee J, Huang W-F, Chen S-M, Cheny H-Y. Survey of medication knowledge and behaviors among college students in Taiwan. Am J Pharm Educ 2006; 70: 30.

9. Nordeng H, Havnen GC. Impact of socio-demographic factors, knowledge and attitude on the use of herbal drugs in pregnancy. Acta Obstet Gynecol Scand 2005; 84: 26-33.

10. Figueiras A, Caamano F, Gestal-Otero JJ. Sociodemographic factors related to self-medication in Spain. Eur J Epidemiol 2000; 16: 19-26.

11. Burak LJ, Damico A, College students' use of widely advertised medications. J Am Coll Health 2000; 49: 118-21.

12. Chang FR, Trivedi PK. Economics of self-medication: theory and evidence. Health Econ 2003; 12: 721-39.

13. Buke C, Limoncu M, Ermevtcan S, Ciceklioglu M, Tuncel M, Kose $\mathrm{T}$, et al, Irrational use of antibiotics among university students. J Infect 2005; 51: 135-9.

14. Lau GS, Lee KK, Luk CT. Self-medication among university students in Hong Kong. Asia Pac J Public Health 1995; 8: 153-7.
15. Vucic VA, Trkulja V, Lackovic Z. Content of home pharmacies and selfmedication practices in households of pharmacy and medical students in Zagreb, Croatia: findings in 2001 with a reference to 1977. Croat Med J 2005;46: 7480.

16. Bauchner $\mathrm{H}$, Wise $\mathrm{P}$. Antibiotics without prescription: "bacterial or medical resistance"? Lancet 2000; 355: 148084.

17. Calabresi P, Cupini LM. Medication-overuse headache: similarities with drug addiction. Trends Pharmacol Sci 2005; 26: 62-8.

18. French L, Horton J, Matousek M. Abnormal vaginal discharge: what does and does not work in treating underlying causes. J Fam Pract 2004; 53: 805-14.

19. Ashina $\mathrm{S}$, Zeeberg $\mathrm{P}$, Jensen $\mathrm{RH}$, Ashina $\mathrm{M}$. [Medication overuse headache]. Ugeskr Laeger 2006; 168: 1015-9.

20. Assael L. The pill culture, the pill society. J Oral Maxillofac Surg 2006; 64:1331-2.

21. Neafsey PJ, Self-medication practices that alter the efficacy of selected cardiac medications. Home Healthc Nurse 2004; 22: 88-98.

22. Tackett B, Smith M, Nedorost S. Morbidity of over-thecounter topical steroids. J Am Acad Dermatol 2006; 54: 182; author reply $182-3$.

23. James H, Handu SS, Khalid AJ, Khaja A, Otoom S, Sequeira RP. Evaluation of the knowledge, attitude and practice of self-medication among first-year medical students. Med Princ Pract 2006; 15: 270-5.

24. Tomson G, Sterky G. Self-prescribing by way of pharmacies in three Asian developing countries. Lancet 1986; 2: 620-2.

25. Vaananen MH, Pietila K, Airaksinen M. Self-medication with antibiotics-does it really happen in Europe? Health Policy 2006; 77: 166-71. 